\title{
Seismic analysis of pile in liquefiable soil and plastic hinge
}

\section{Rohollah Rostami MSc}

PhD researcher, Glasgow Caledonian University, Glasgow, UK

(corresponding author: rrosta200@caledonian.ac.uk)

(Orcid:0000-0003-3477-9182)

Nicholas Hytiris PhD

Senior Lecturer, School of the Built and Natural Environment, Glasgow

Caledonian University, Glasgow, UK (Orcid:0000-0002-2159-7737)

\author{
Subhamoy Bhattacharya PhD \\ Professor, Chair in Geomechanics, University of Surrey, Guildford, UK \\ Martin Giblin MEng \\ Design Engineer, Tony Gee and Partners, London, UK
}

\begin{abstract}
Liquefaction is one of the leading seismic actions that cause extensive damage to buildings and infrastructure during earthquakes. In many historic cases, plastic hinge formations in piles were observed at inexplicable locations. This project investigated the behaviour of piled foundations within soils susceptible to liquefaction by using numerical analysis carried out in Abaqus software in terms of plastic hinge development. Three different soil profiles were considered in this project that varied in the thickness of both the liquefiable and non-liquefiable layers, pile length and free- and fixed-head pile conditions. Modelling a single pile as a beam-column element carrying both axial and El Centro record earthquake loading produced results of the seismic behaviour of piles that could be assessed by force-based seismic design approaches. The displacements and deformations induced by dynamic loads were analysed for piles affected by liquefaction, and the results were used to demonstrate the pile capacity and discuss the damage patterns and location of plastic hinges. Parametric studies generally demonstrate that plastic hinge formation occurs at the boundaries of the liquefiable and non-liquefiable layers; however, the location can be affected by a variety of factors such as material properties, pile length and thickness of the liquefied soil layer.
\end{abstract}

\section{Notation}

$a_{0} \quad$ dimensionless frequency

$C$ damping matrix

$c_{\mathrm{u}} \quad$ cohesion

$D \quad$ pile diameter

$d_{\mathrm{bl}} \quad$ diameter of longitudinal reinforcing steel

$E_{\mathrm{s}} \quad$ soil modulus

$f_{\mathrm{c}}^{\prime} \quad$ compressive strength of unconfined concrete

$f_{\mathrm{y}} \quad$ yield strength

$H_{\text {o-max }}$ length of pile shaft/column from the point of maximum moment to point of contra flexure above ground

$I_{\mathrm{u}} \quad$ kinematic displacement

K stiffness

$L$ distance from the critical section to the point contra flexure

$L_{\mathrm{a}} \quad$ above-ground height

$L_{\mathrm{p}} \quad$ plastic hinge length

$L_{\mathrm{a}}^{*} \quad$ normalized above-ground height

$L_{\mathrm{p}}^{*} \quad$ function of above-ground height

M mass

$U_{\text {ff }} \quad$ amplitude of free-field motion

$U_{\mathrm{p}} \quad$ response of the top of the pile

$V_{\mathrm{s}} \quad$ shear wave velocity of soil

$y \quad$ lateral deflection of the pile

$\gamma_{\text {dry }}$ effective unit weight

$\delta_{\max } \quad$ maximum displacement

$\delta_{\mathrm{y}} \quad$ yield displacement

$\varepsilon_{\mathrm{c}} \quad$ concrete strain

$\zeta \quad$ viscous damping ratio

$\theta_{\mathrm{p}} \quad$ plastic rotation in the pile

$\begin{array}{ll}\mu_{\Delta} & \text { displacement ductility } \\ \mu_{\delta} & \text { curvature ductility } \\ \sigma_{\mathrm{y}} & \text { yield strength } \\ v & \text { Poisson's ratio } \\ \Phi & \text { friction angle } \\ \phi_{\mathrm{m}} & \text { maximum curvature } \\ \phi_{\mathrm{p}} & \text { plastic curvature } \\ \phi_{\mathrm{y}} & \text { equivalent elasto-plastic yield curvature } \\ \omega & \text { circular frequency of loading }\end{array}$

\section{Introduction}

The seismic risk assessment of pile-supported structures in liquefiable soils during an earthquake is an important issue. Pile foundations are commonly installed to support heavy loads when near-surface soils are too weak or too compressible to support the loads without excessive settlement or lateral deflection (Kramer, 2014). Liquefaction happens when, during earthquake shaking, the pore water pressure of loosely deposited sandy soil layers increases rapidly and sufficiently and the effective stress in the soil can decrease to zero (Booth, 1994: p. 277). Collapse and damage of pile-supported structures due to liquefaction are still observed in many major earthquakes (Lombardi and Bhattacharya, 2016). The pile-supported structures' response to liquefiable soils during a major earthquake depends on the stiffness of the pile foundation, response of soil surrounding the pile and soil-pile interaction effects. The interactions are classified as inertial loading exerted by the superstructure and kinematic loading induced by the soil surrounding the pile. The Japanese highway code of practice (JRA, 2002) advises practising engineers to consider both loading conditions; however, it also suggests checking against bending failure due to kinematic and inertial forces separately. Similarly, Eurocode 
(EC) 8 (BSI, 2004) advises engineers to design piles against bending due to inertial and kinematic forces arising from the deformation of the surrounding soil. In the event of liquefaction, EC 8 (BSI, 2004: p. 26) also suggests the following: 'the side resistance of soil layers that are susceptible to liquefaction or to substantial strength degradation shall be ignored'. The National Earthquake Hazards Reduction Program (Fema, 2000) also focuses on the bending strength of the piles by treating them as laterally loaded beams and assuming that the lateral load due to inertia and soil movement causes bending failure. Current research has indicated that there are two different mechanisms of pile failure in liquefiable soils: failure through bending or through buckling instability (Abdoun and Dobry, 2002; Bhattacharya, 2003; Bhattacharya and Goda, 2013; Bhattacharya and Madabhushi, 2008; Bhattacharya et al., 2004; Dash et al., 2010; Finn and Fujita, 2002; Goh and O'Rourke, 1999; Hamada, 1992; Ishihara, 1997; Tokimatsu and Asaka, 1998). The first mechanism is the bending failure that can occur when soil liquefies and loses much of its stiffness, causing the piles to act as unsupported slender columns. The second mechanism is the buckling instability of the piles when acting as beam columns under both axial and lateral loading. Despite the extensive research in this field, these mechanisms cannot explain the damage patterns and location of plastic hinges in the piles. In many historic cases, plastic hinge formation occurred at inexplicable locations. For example, Bhattacharya and Madabhushi (2008) reported that investigations had found the failure pattern of the piles described by Yoshida and Hamada (1990) and BTL Committee (2000) (see Figure 1). They mentioned that the cracks observed were near the bottom and top boundaries between liquefied and nonliquefied layers and often at the pile head. Additionally, they found plastic hinges had also formed at the boundaries of the liquefiable and non-liquefiable layers and at various depths between. Therefore, the

Depth: $m$

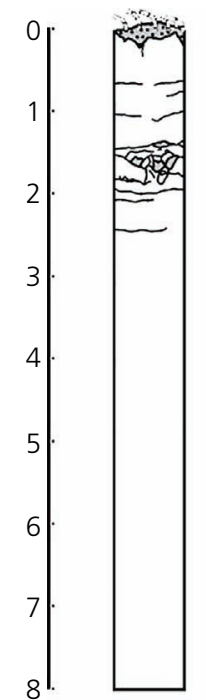

Depth: $m$

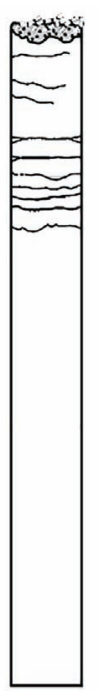

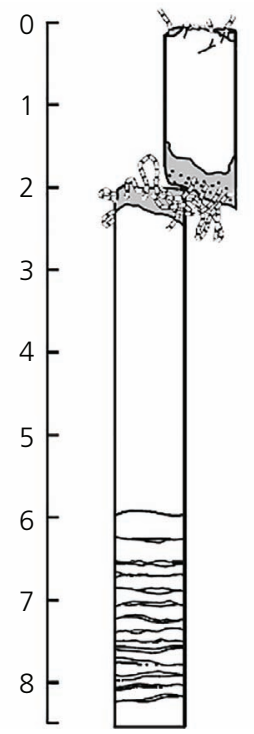

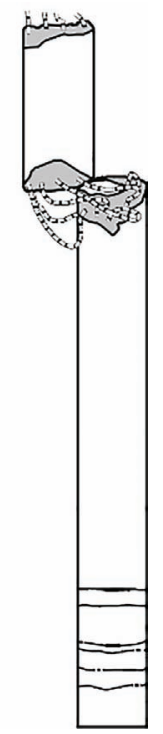

Figure 1. Pile damage of a building in Niigata City (Bhattacharya and Madabhushi, 2008; Yoshida and Hamada, 1990) main aims of this study are to present the analysis of liquefaction and explain the damage patterns and location of plastic hinges. A numerical approach (with consideration to a comprehensive modelling framework of different soils profiles) is presented. In this paper, the seismic behaviour of the piles can be assessed by force-based seismic design (FBSD) approaches.

\section{Methodology}

This study investigated the development of three-dimensional (3D) finite-element models (FEMs) for the behaviour of pile-supported structures in liquefaction soils in terms of plastic hinge development. The work scope initially describes the 3D model for three different soil profiles with the pile modelled as a beam-column element carrying both axial and El Centro earthquake record earthquake loading. The FBSD was used in this research to assess the seismic behaviour of pile-supported structures in liquefiable soils. The displacement and deformation demands induced by dynamic loads were analysed for piles affected by liquefaction by using $p-y$ curves to performance of pile bending moments. The results of the seismic behaviour will be used to demonstrate the capacity of the pile and discuss the damage patterns and location of plastic hinges.

\section{$p-y$ curves for modelling liquefiable soils}

The non-linear $p-y$ curves of the liquefied soil used in the modelling of soil-pile-structure interaction is based on the beam on elastic foundation approach (Hetényi, 1946). The $p-y$ curves have been used to model the reaction of the foundation with consideration of inertial effects and seismic soil-pile interaction. Because the soil stiffness may change due to pore water pressure generation, numerous researches have been carried out to evaluate $p-y$ curves for piles in liquefiable soils, such as Dobry et al. (1995), Yasuda et al. (1998), RTRI (1999), AIJ (2001), Takahashi et al. (2002) and Rollins et al. (2005). Bhattacharya et al. (2005) suggested an S-curve shape of the ' $p-y$ ' curve for liquefied soil. Maheshwari and Sarkar (2011) and Sarkar and Maheshwari (2012) used the Drucker-Prager soil model of work hardening to investigate the 3D behaviour of single piles and pile groups. Lombardi and Bhattacharya (2016) and Dash et al. (2017) adopted a new set of $p-y$ curves that can be obtained by modifying the conventional $p-y$ curves (for non-liquefied soils) in such a way that replicates the strain hardening behaviour aforementioned. In this research, the non-linear spring stiffness $(p-y$ curves) of the liquefied soil are used to evaluate soil-pile interaction analysis performed pile bending moments.

\section{Overview of models}

The models vary between one, two and three distinct layers of soil. The soil layers consisted of two thick layers of nonliquefiable soil and one liquefiable soil. A reinforced concrete pile was located in the middle of the soil system, with the soil layers in the models varying in thickness, articulation and soil type. Due to its symmetry, half of the pile and surrounding soil is modelled. The different soil profiles surrounding the pile are considered to be wide enough to identify the effectiveness of the free-field kinematic demand imposed on the soil system. Additionally, these models are deemed sufficiently comprehensive enough in order to 
Seismic analysis of pile in liquefiable soil

and plastic hinge

Rostami, Hytiris, Bhattacharya and Giblin understand the behaviour of the pile from any effects induced by liquefaction on the soil-structure interaction.

\section{Boundary conditions}

For the FEM to simulate effectively the pile-soil interaction, it was important to define the boundary conditions appropriately. The dynamic load model requires boundary conditions that offer support to the elements while restricting unnecessary motions. For dynamic cases, the ability of the infinite elements to transmit energy out of the finite-element (FE) mesh, without trapping or reflecting it, is optimised by making the boundary between meshes as close as possible to being orthogonal to the direction from which the waves will impinge on the boundary. Close to a free surface, where Rayleigh or Love waves may be important, the FEs are most effective if they are orthogonal to the surface (Abaqus Inc., 2012). This is illustrated in Figure 2.

\section{Dynamic loading}

After seismic actions had been imported into the models, displacement and deformation demands were analysed by using three parameters: vibration period, equivalent viscous damping and ductility capacity. Seismic loading was applied at the bedrock level in the horizontal direction as acceleration time history. The input motion of harmonic excitation consisted of waves of unit amplitude and different frequencies for the first $8.00 \mathrm{~s}$ of the El Centro earthquake record scaled to $0 \cdot 30 \mathrm{~g}$ and used as the base input acceleration (shown in Figure 3). However, the input motion was applied at $0 \cdot 15 \mathrm{~g}$ due to the larger values of initial effective stress at the lower layers (Rahmani and Pak, 2012). The axial load was applied throughout the seismic loading of $1100 \mathrm{kN}$ (Figure 4) to simulate that the increasing axial load due to equilibrium is satisfied within the soil layers.

\section{Damping}

The second parameter required for FBSD is damping. Normally, in both verification and dynamic analyses associated with viscous damping, a ratio of $5 \%$ is typically used for the Rayleigh type. There are two kinds of damping properties for soil dynamics that can be considered - namely, material damping and geometrical damping. Rayleigh damping is a form of material damping with

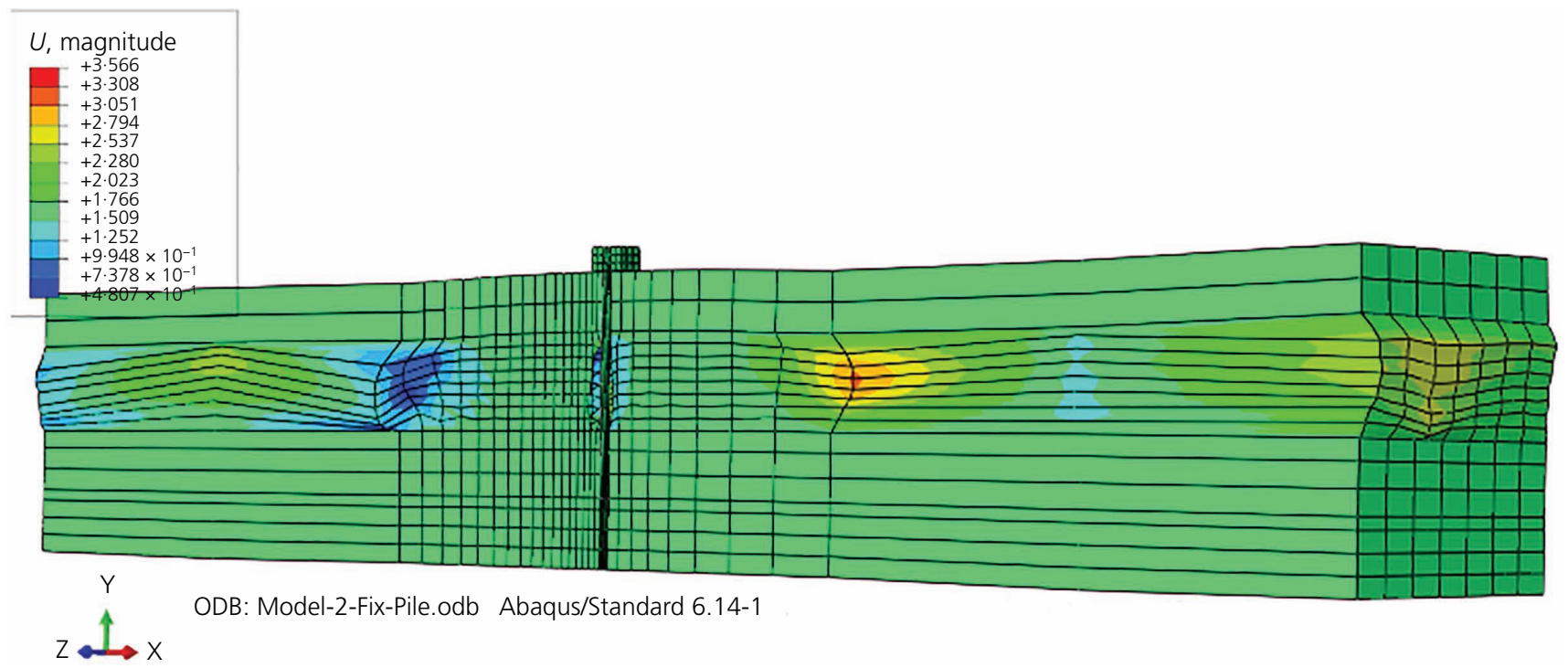

Figure 2. Deformed shape for fixed head of case II

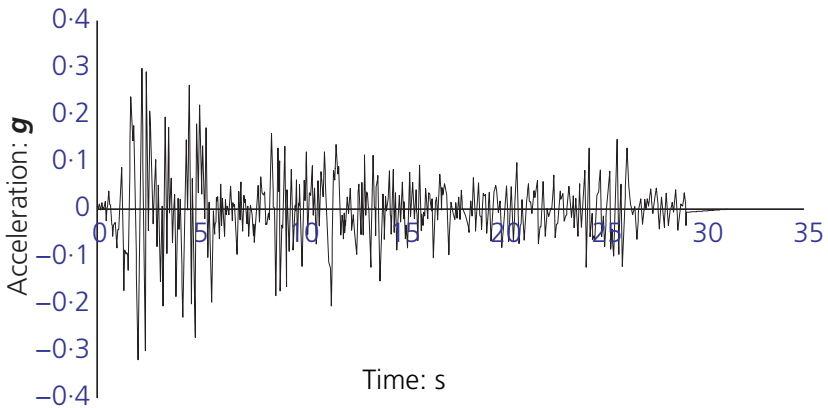

Figure 3. Acceleration record of El Centro (1940) earthquake

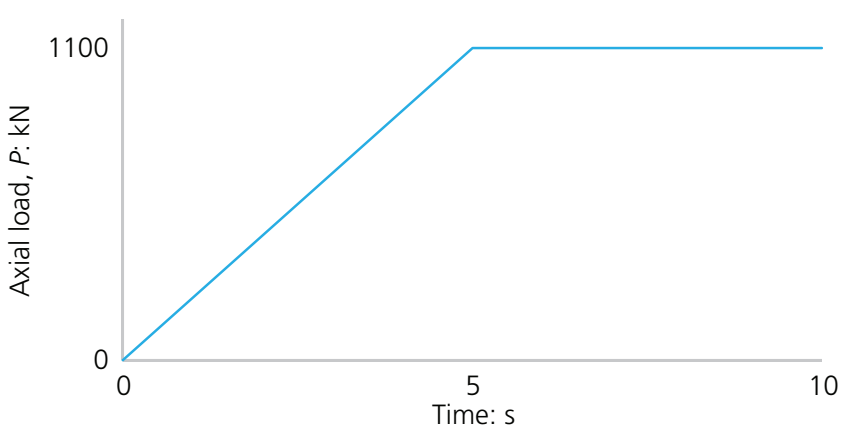

Figure 4. Increase of axial load $P$ over time 
mass and stiffness expressed by $C, M$ and $K$, respectively, which are represented by the equation

1. $C=\alpha M+\beta K$

To determine the values for the Rayleigh damping ratio in the Abaqus software, the natural frequencies of the soil-structure system were modelled and then solved for the constants $\alpha$ and $\beta$ to give a viscous damping ratio $\zeta$. The effects induced by soil liquefaction increase the damping ratio, which can reach values as high as 20\% (Lombardi and Bhattacharya, 2014).

\section{Ductility}

Ductility is defined as the ratio of the maximum displacement to the yield displacement

2. $\mu_{\delta}=\delta_{\max } / \delta_{\mathrm{y}}$

Ductility in the FBSD is based on the inelastic response spectrum of a single-degree-of-freedom system with elastic-perfectly plastic force-displacement curve (Fardis, 2009). Ductility may be significantly lower in liquefaction conditions (Lombardi and Bhattacharya, 2014). Displacement ductility demand is defined as the ratio of global frame displacement demand to the yield displacement.

\section{Material modelling}

To model accurately a pile that is pushed through a soil profile containing a liquefied layer, it is important to use a comprehensive constitutive model with a relatively high degree of resolution to capture the interaction between the pile and the soil. Accordingly, the meshes of regions near the liquefiable soils of the pile are comparatively more important. The vertical size mesh of the soil and pile elements is of a somewhat larger scale at the boundaries, gradually decreasing into the liquefied layer, with the smallest elements existing in the middle of that layer. Similarly, the horizontal size of the soil elements is large at the boundaries of the model and becomes smaller as the radial distance to the centre of the pile decreases.

\section{Modelling the pile}

The piles in this study include one deep foundation reinforced concrete pile modelled using beam-column elements. The pile model is based on a template of a reinforced concrete pile. The piles were selected such that they represent a reasonable variation in size and stiffness, thus providing data that are relevant to the range of size and stiffness where most practical pile designs fail. Precast piles typical in construction, consisting of a $0.6 \mathrm{~m}^{2}$ section and with lengths of 9 and $12 \mathrm{~m}$, were modelled. Figures 5 and 6 show the scale model and scale section view of pile. The material property values of piles and raft models are provided in Tables 1 and 2 (Banerjee and Shirole, 2014).

\section{Modelling the soil}

In this study, three typical 3D models of soils surrounding the piles were considered, varying the thicknesses of liquefied and non-liquefied layers and material properties to define how a pile experiences a liquefaction phenomenon event. Appropriate values for the soil parameters were chosen from previous case histories (Sarkar et al., 2014) to ensure valid results. The soil parameters selected for the FEM are summarised in Tables 3 and 4 .

During earthquakes, the pore water pressure increases in the liquefiable layer, thus reducing the effective stress in the layer and subsequently the shear strength becomes significantly smaller. As a result, the compressibility of the layer cannot change quite as

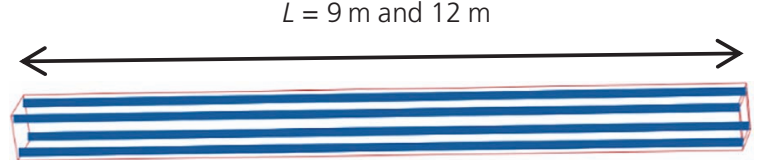

Figure 5. Details of the pile

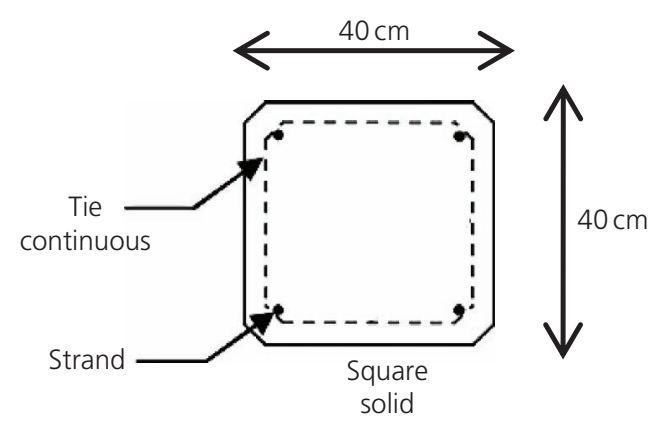

Figure 6. Cross-sections of concrete piles

Table 1. Material property values of pile model

\begin{tabular}{|lcccc|}
\hline Pile: $\mathbf{m}$ & $\mathbf{E}: \mathbf{G P a}$ & $\sigma_{\boldsymbol{y}}: \mathbf{M P a}$ & $f_{\mathrm{c}}^{\prime}: \mathbf{k P a}$ & $\boldsymbol{E}_{\mathbf{c}}$ \\
\hline 9 & 31.3 & 1860 & 44816 & 0.03 \\
12 & 31.3 & 1860 & 44816 & 0.03 \\
\hline
\end{tabular}

Table 2. Properties of piles and raft models

\begin{tabular}{|lccc|} 
Pile: $\mathbf{m}$ & $\begin{array}{c}\text { Pile } \\
\text { Poisson's ratio }\end{array}$ & $\begin{array}{c}\text { Modulus of } \\
\text { elasticity: } \mathbf{k N} / \mathbf{m}^{\mathbf{2}}\end{array}$ & $\begin{array}{c}\text { Unit weight: } \\
\mathbf{k N} / \mathbf{m}^{3}\end{array}$ \\
\hline 9 & 0.15 & $30 \times 10^{6}$ & 24 \\
12 & 0.15 & $30 \times 10^{6}$ & 24 \\
Raft & 0.2 & $25 \times 10^{6}$ & 23.5 \\
Steel material & 0.3 & $200 \times 10^{6}$ & 78.5
\end{tabular}

Table 3. Properties of soil models

\begin{tabular}{|lrcrc|} 
Soil layer & $\boldsymbol{E}: \mathbf{k P a}$ & $\boldsymbol{v}$ & $\boldsymbol{G}: \mathbf{k P a}$ & $\boldsymbol{K}: \mathbf{k P a}$ \\
\hline Non-liquefiable & 25000 & 0.35 & 9260 & 27777.8 \\
Liquefiable & 2500 & 0.485 & 842 & 27777.8
\end{tabular}


Seismic analysis of pile in liquefiable soil

and plastic hinge

Rostami, Hytiris, Bhattacharya and Giblin

Table 4. Soil parameters

\begin{tabular}{|c|c|c|c|c|c|}
\hline & Layer & Basic description & Unit weight: $\mathrm{kN} / \mathrm{m}^{3}$ & Cohesion, $c_{\mathrm{u}}: \mathrm{kPa}$ & Friction angle, $\Phi:^{\circ}$ \\
\hline & 1 & Soft silty clay & $19 \cdot 1$ & $40 \cdot 0$ & - \\
\hline & $\|$ & Soft clayey silt & $18 \cdot 2$ & $23 \cdot 0$ & - \\
\hline \multirow[t]{4}{*}{ Liquefiable zone } & III & Loose sandy silt & $18 \cdot 0$ & - & $28 \cdot 0$ \\
\hline & IV & Medium dense silty sand & $19 \cdot 0$ & - & $30 \cdot 0$ \\
\hline & V & Stiff clayey silt & $18 \cdot 4$ & $49 \cdot 0$ & - \\
\hline & $\mathrm{Vl}$ & Medium dense silty sand & $19 \cdot 0$ & - & $32 \cdot 0$ \\
\hline
\end{tabular}

drastically. Therefore, the soil material parameters are selected based on an assumption that the bulk modulus $\mathrm{K}$ remains consistent throughout the soil mass and the Poisson's ratio of liquefiable soils is selected as $v=0.485$ (McGann et al., 2012). Additionally, the Mohr-Coulomb failure criterion is used to simulate the behaviour of soils (Helwany, 2007).

\section{Modelling the soil-pile system}

To model the interaction between the soils and pile, the 'surfaceto-surface' contact method was used. This system is called a 'master-slave' surface, where the more deformable and more rigid surfaces are defined as the 'slave' and 'master' surfaces, respectively. This is well explained in Abaqus 6.12 (Abaqus Inc., 2012). The three models of soil profiles are shown in Figures 7-9.

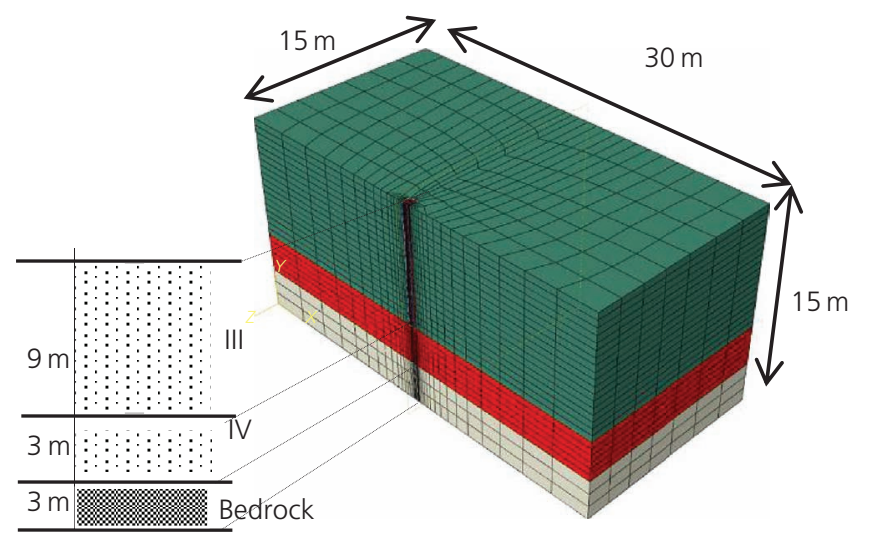

Figure 7. Case I, liquefiable soil

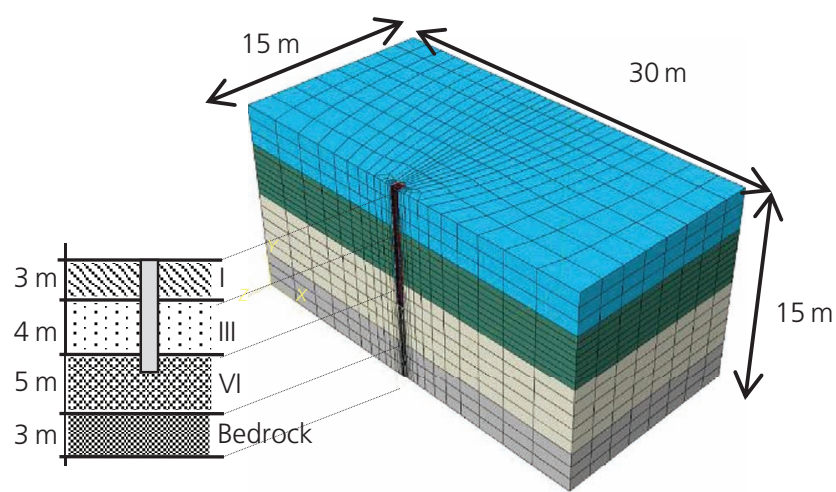

Figure 8. Case II, liquefiable layer between non-liquefiable layers

\section{Validation of models}

In computer simulations, it is important to create validation models that behave in response to verifiable loading conditions. In the first step, the validations for kinematic loading interaction are carried out by using the study by Fan et al. (1991). This study was conducted on the kinematic soil-pile interaction in the frequency domain. They defined two factors, kinematic displacement $\left(I_{\mathrm{u}}\right)$ and dimensionless frequency $\left(a_{0}\right)$, given by Equations 3 and 4

3. $I_{\mathrm{u}}=\frac{\left|U_{\mathrm{p}}\right|}{\left|U_{\mathrm{ff}}\right|}$

where $U_{\mathrm{p}}$ is the response of the top of the pile and $U_{\mathrm{ff}}$ is the amplitude of free-field motion

4. $\quad a_{0}=\frac{\omega D}{V_{\mathrm{s}}}$

where $\omega$ is the circular frequency of loading, $D$ is the pile diameter and $V_{\mathrm{s}}$ is the shear wave velocity of soil.

Figure 10 shows the result (at lower frequency) of the model that was subjected to $a_{0}=0 \cdot 3 \mathrm{~g}$. It can be seen that the result of the 3D model is in good agreement with that of Fan et al. (1991).

In this study, for validation of combined kinematic and inertial interactions, the amplitude of the input bedrock motion was

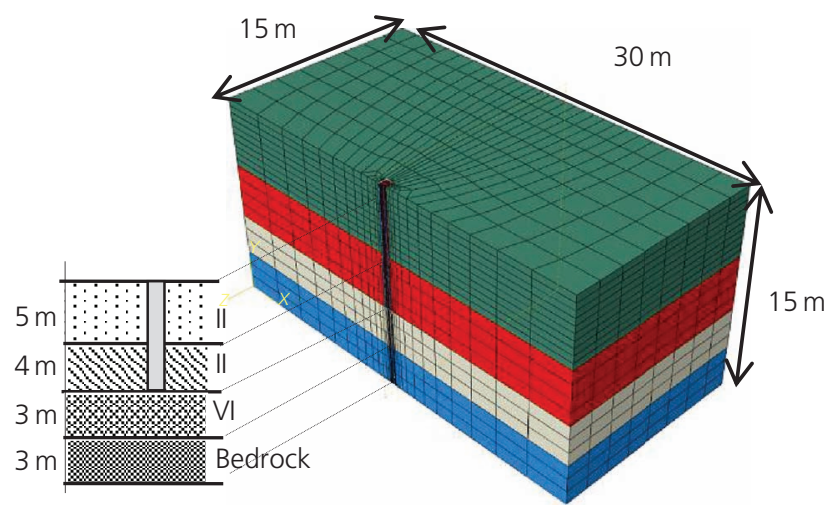

Figure 9. Case III, upper layer is liquefiable soil 


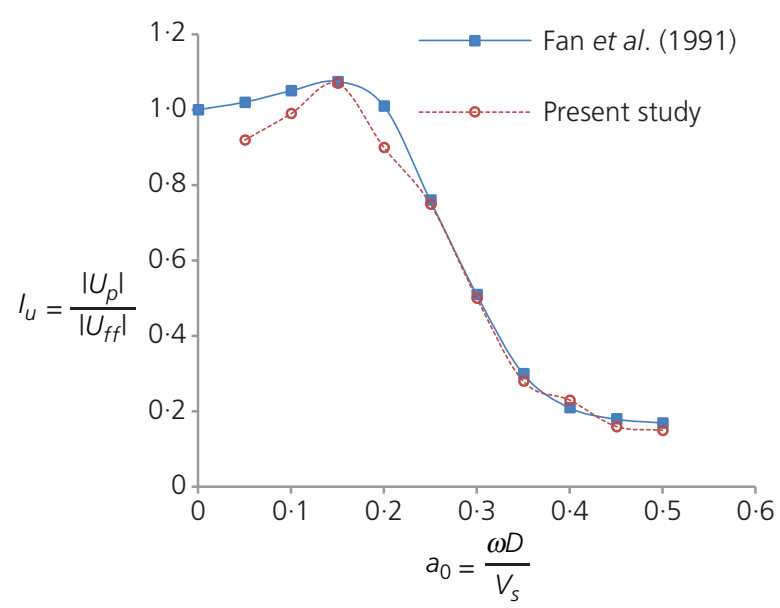

Figure 10. Verification of kinematic loading

inputted at different frequencies compared with the frequency response function (FRF) of Lombardi and Bhattacharya (2014). The FRF is a function that describes the relationship between the input (motion) and output (response) of the structure, and it is considered in Abaqus by using frequency analysis. Figure 11 verifies that the results from the $3 \mathrm{D}$ model correlate with the empirical model.

In the next step, results of Blandon's model pile response (Blandon, 2007) and the Winkler approach are used to demonstrate the capability of the model for reliable analysis of piles. Blandon (2007) modelled a $9 \mathrm{~m}$ pile in soil layers that was the same as case II, and a $0.60 \mathrm{~m}$ layer was assumed to liquefy due to the seismic event. Also, the Winkler method, as a standard and common method of analysis, is widely used in practice. The Alp (Analysis of Laterally Loaded Piles) software, which is based on the Winkler approach, is used for modelling. As shown in Figure 12, the result obtained from the 3D FEM agrees reasonably well with the values recorded of Blandon's model pile response and the Winkler approach.

\section{Analysis of 3D FEM}

In order to analyse the seismic risk of pile-supported structures in liquefiable soil layers and discuss the plastic hinges, a parametric study has been carried out on three different soil profiles, varying the boundary conditions of the pile head and the length and

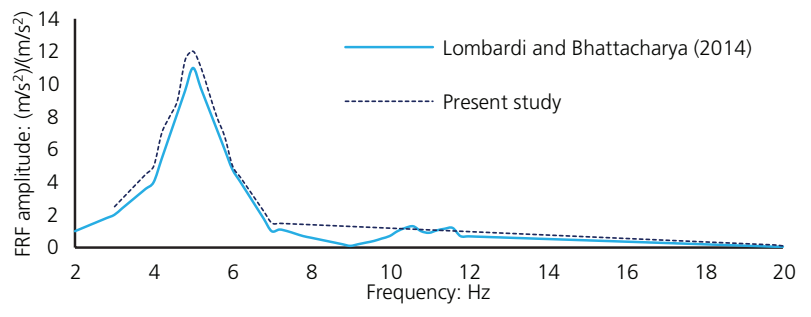

Figure 11. Dynamic verification for pile-head response

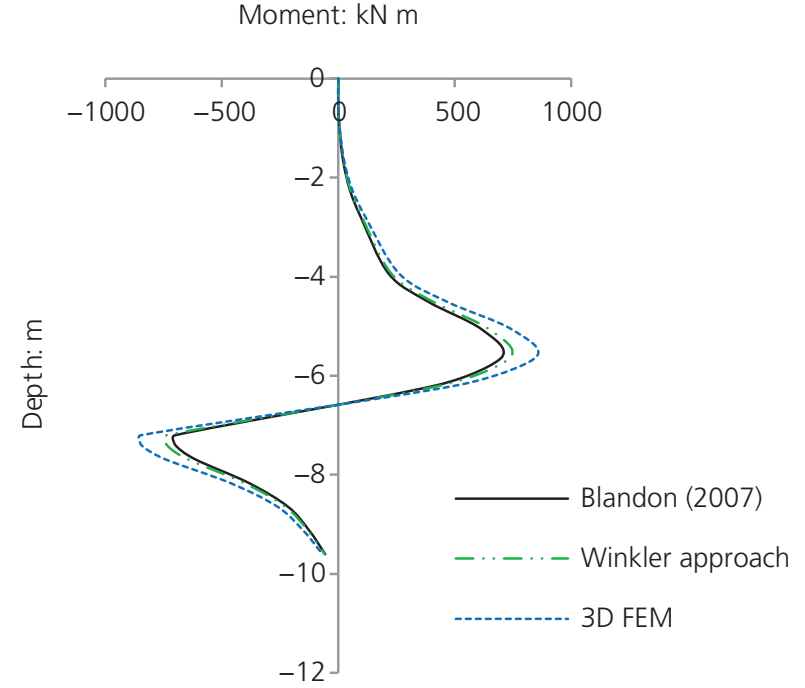

Figure 12. Verification of results

location of the liquefied soil layer along the pile. The seismic displacement method adopted in this research to evaluate the soil-pile interaction of the liquefied soil analysis is normally performed in terms of pile bending moments the use of non-linear $p-y$ curves. However, the bending moments could not be directly obtained from the Abaqus output as the pile was modelled as a solid element. This restriction may be overcome by adding a very flexible beam element along the pile axis (Banerjee and Shirole, 2014).

\section{Pile response}

The pile response was governed by the respective material properties, length, free or fixed head condition and the surrounding soil. The behaviour at each incremental point along the pile length was observed. The deformed shape of the systems and the interaction between the soil and the pile are shown in Figure 13, which also illustrates the maximum bending moment in the pile in all of the cases. From the deformed shape of the systems, it can be observed that the imposed displacement profile puts the pile in bending. It can also be seen that the nonliquefiable layers of the soil begin to displace laterally with respect to the liquefiable layer. However, the pile provides resistance to this motion as the upper portion is pushed along with the flow of soil. This behaviour is illustrated by the deformed shape of the systems. For case I, the deformed shape illustrates that the lateral stress distribution and the locations of the maximum bending moment are likely to occur at the middle of the pile at the depth of the liquefiable soil for both free- and fixed-head piles. In case II, it can clearly be seen that in the lower solid layer, the pile pushes into the soil at the interface with the liquefied soil layer. In the upper soil layer, it is observed that the pile resists the ground motion at the interface with the liquefied layer and is pushed into the soil at the pile head. Therefore, the locations of the large bending moment are attained in the soil 

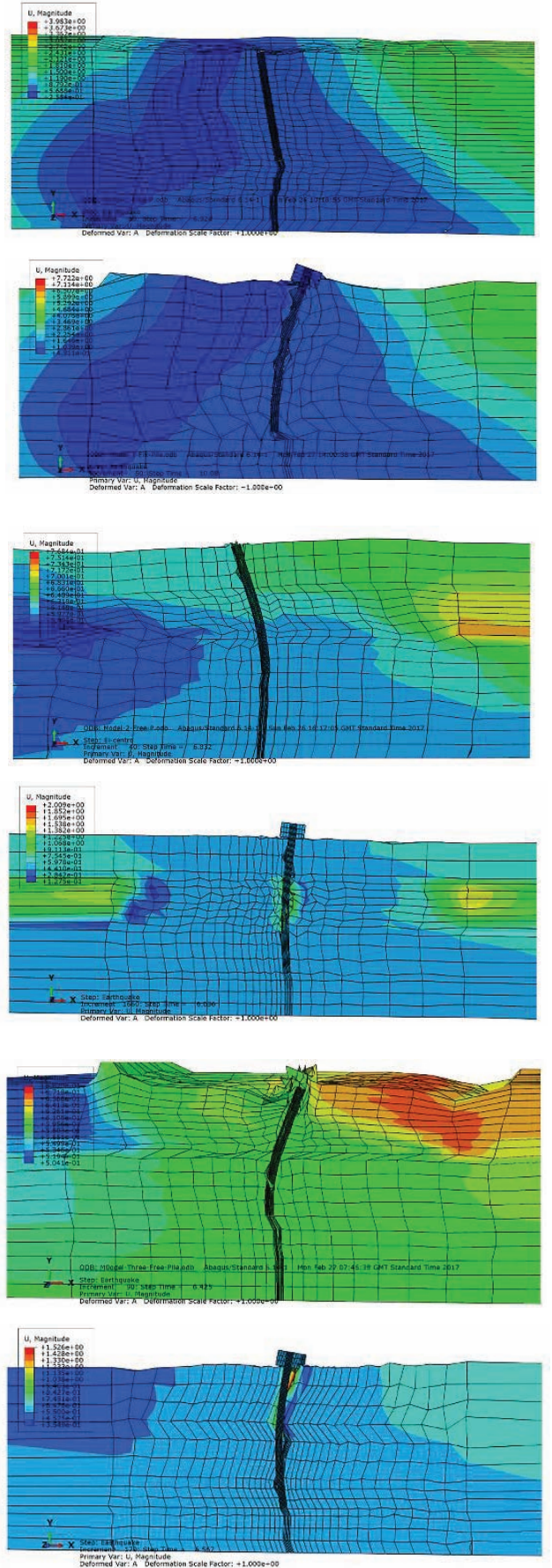

Maximum bending moment: $\mathrm{kNm}$
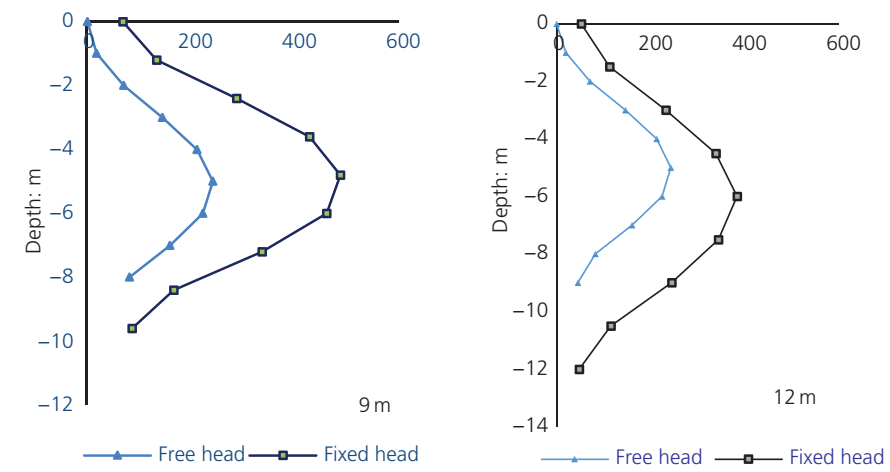

Maximum bending moment: $\mathrm{kN} \mathrm{m}$

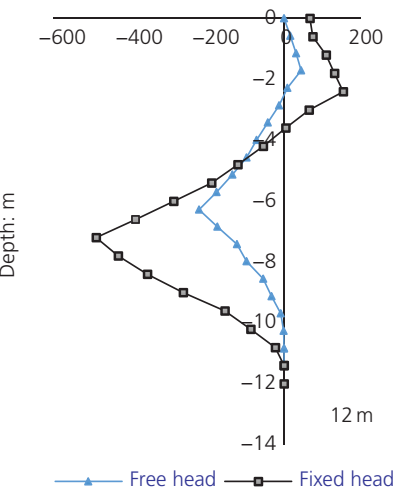

Maximum bending moment: $\mathrm{kN} \mathrm{m}$

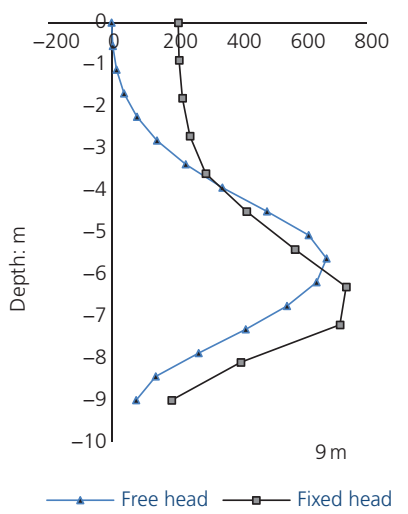

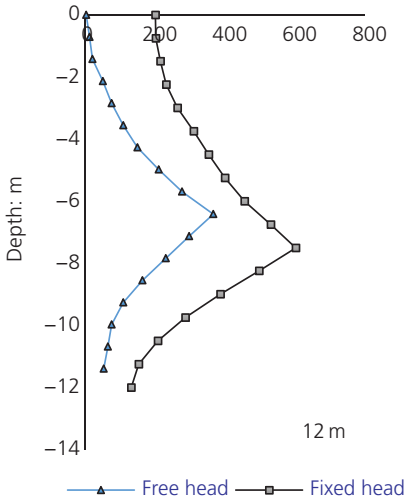

Figure 13. Deformed shape and maximum bending moment $(\mathrm{kN} \mathrm{m})$ for both free- and fixed-head piles in cases I to III

layers at the boundaries of models. For case III, the maximum of the bending moment invariably develops at the boundaries of liquefiable and non-liquefiable soil layers, similarly to that of case II. It also can be concluded that the pile length has no effect on the location of the maximum bending moment. According to the assumptions of soil parameters mentioned in section headed 'Modelling the soil', Figure 14 shows the excess pore water pressure generated near pile $5 \mathrm{~m}$ deep of the surface for cases I, II and III. The different time history in each case can be seen.

\section{Effects of pile head condition}

Both free- and fixed-head pile conditions were considered in this study, with the fixed head pile simulating a rigid pile cap preventing the pile head from rotating. It is observed for all cases 
Seismic analysis of pile in liquefiable soil

and plastic hinge

Rostami, Hytiris, Bhattacharya and Giblin
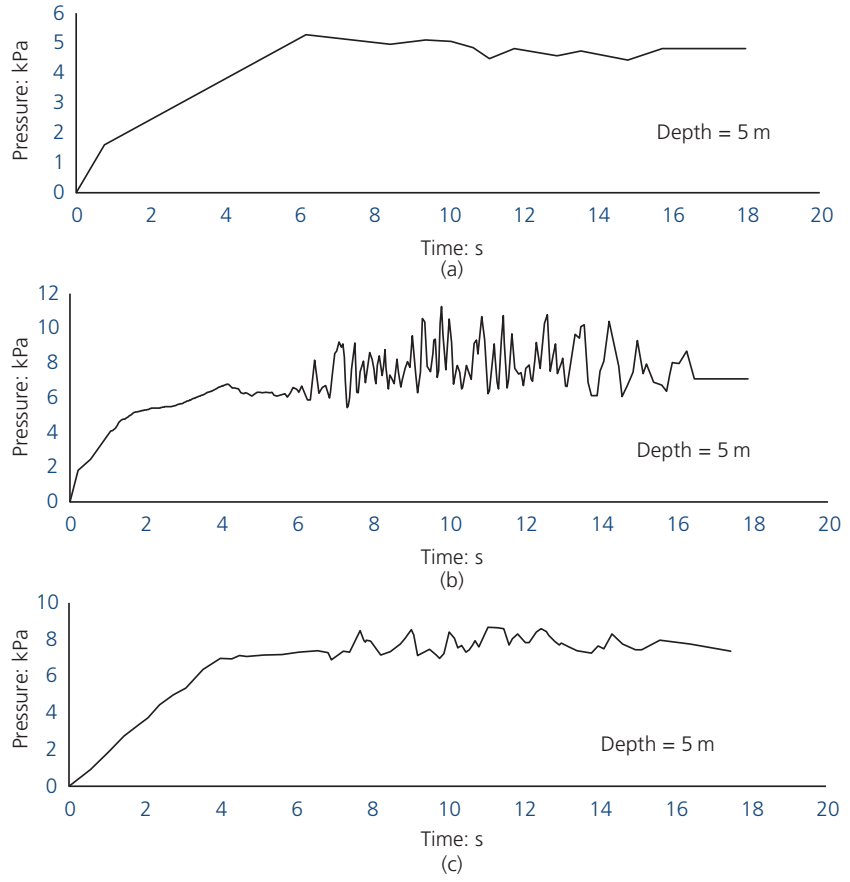

Figure 14. Pressure generated near pile: (a) case I, (b) case II and (c) case III of fixed-head pile

in Figure 13 that the maximum moment demands of fixed head piles are greater than, or approximately equal to, the demands resulting from the corresponding free-head cases.

\section{Effects of pile length}

Two different pile lengths (9 and $12 \mathrm{~m}$ ) were modelled. From Figure 15, it can be seen that longer piles experience larger displacements, as a greater amount of the longer pile is in contact with the liquefiable soil. This affect, however, has relatively little effect. Another interesting observation is that maximum lateral displacement decreases for the fixed head condition.

\section{Results}

The data obtained from the FEMs performed in this research are used in this section to demonstrate the capacity of the pile founded in liquefiable soils in terms of plastic hinge development.

\section{Plastic hinges}

The FBSD for ductility is based on the inelastic response of spectral acceleration and the maximum displacement demand expressed as a ratio to the yield displacement (Equation 2). Each member is entrusted through 'capacity design' for inelastic deformations and ability to undergo dependable deformation in plastic hinge regions without experiencing brittle failure. The minimum local displacement ductility capacity of $\mu_{\Delta}=3$ was used, based on suggestions of ATC-32 (ATC, 1996) to ensure dependable rotational capacity in the plastic hinge regions regardless of the displacement demand imparted to that member.

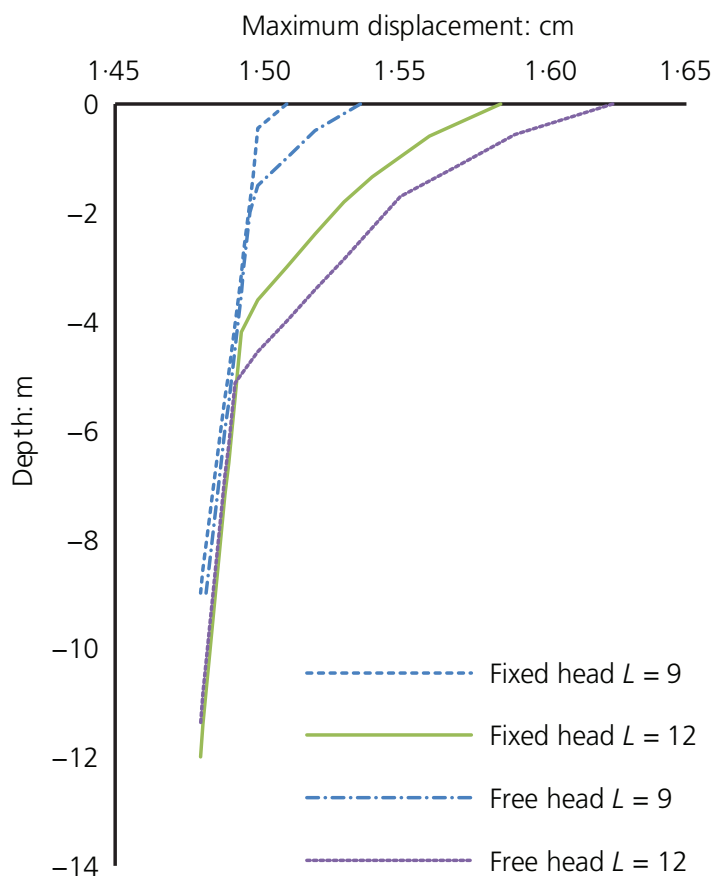

Figure 15. Maximum displacement (case I): $\mathrm{cm}$

The analytical plastic hinge length is assumed constant for estimating Equation 5 (Priestley et al., 1996)

5. $L_{\mathrm{p}}=0 \cdot 08 L+0 \cdot 022 f_{\mathrm{y}} d_{\mathrm{bl}} \geq 0 \cdot 044 f_{\mathrm{y}} d_{\mathrm{bl}}$

where $L$ is the distance from the critical section to the point contra flexure, $f_{\mathrm{y}}$ is the yield strength and $d_{\mathrm{bl}}$ is the diameter of longitudinal reinforcing steel. Budek et al. (2000) suggested Equation 6 , where $L_{\mathrm{p}}^{*}$ is a function of above-ground height and maximum $L_{\mathrm{p}}^{*}=1.6 \mathrm{~m}$

6. $L_{\mathrm{p}}^{*}=0 \cdot 1 L_{\mathrm{a}}^{*}+1 \leq\left(L_{\mathrm{p}}^{*}\right)_{\max }$

where $L_{\mathrm{p}}^{*}=L_{\mathrm{p}} / D$ and $L_{\mathrm{a}}^{*}=L_{\mathrm{a}} / D$.

The California Department of Transportation (Caltrans, 2006) also suggests that the plastic hinge length can be calculated by following Equation 7

7. $L_{\mathrm{p}}^{*}=0 \cdot 08 H_{\mathrm{o}-\max }^{*}+1 \cdot 0$

where $H_{\mathrm{o}-\max }^{*}=H_{\mathrm{o}-\max } / D, D$ is the diameter of circular shafts or the least cross-sectional dimension of oblong shafts and $H_{\mathrm{o}-\max }$ is the length of pile shaft/column from the point of maximum moment to point of contra flexure above ground. 
For the FE analyses, maximum curvature demand was determined as Equation 8

8. $\phi_{\max }=\frac{\phi_{\mathrm{p}}+\phi_{\mathrm{y}}}{\phi_{\mathrm{y}}}=\frac{\phi_{\mathrm{p}}}{\phi_{\mathrm{y}}}+1$

Therefore, the plastic hinge length can be determined as Equation 9

9. $L_{\mathrm{p}}=\frac{\theta_{\mathrm{p}}}{\phi_{\mathrm{p}}}=\frac{\theta_{\mathrm{p}}}{\phi_{\mathrm{m}}-\phi_{\mathrm{y}}}$

where $\theta_{\mathrm{p}}$ is the plastic rotation in the pile and $\phi_{\mathrm{p}}$ is the plastic curvature. Zhang and Hutchinson (2012) used static pushover analysis and provided a strategy by integrating the calculated plastic curvature at all integration points along the pile shaft. As mentioned before, a very flexible beam element was added along the pile axis (Banerjee and Shirole, 2014) to perform bending moments (Figure 13), the maximum values of shear force and displacement, $\max U$ for the pile. Equation 7 was used in calculating the plastic hinge length values. Figure 16 shows the maximum curvature distribution of pile for the non-linear beam elements in Abaqus at a displacement ductility $\mu_{\Delta}=3$ and using the strategy of Zhang and Hutchinson (2012).

\section{Effects of liquefaction}

It is observed that the plastic hinge length is based on the pile diameter, reinforcing steel ratio, ductility and soil conditions. However, the results shown in Figure 16 demonstrate the effect of the liquefiable soils. The observation of the pile response has confirmed that the location of plastic hinges is in extreme moment and occurs at the boundaries between the liquefiable and nonliquefiable layers.
It is noted that in a homogeneous liquefiable soil, plastic hinges can likely occur in the middle of the pile. It can also be concluded that the length of plastic hinges $L_{\mathrm{p}}^{*}$ is related to soil conditions and the increase in liquefiable soil is due to an increase in the maximum moment.

\section{Conclusion}

This paper presents 3D soil-pile interaction models that were created for three cases of liquefiable and non-liquefiable soils by using numerical analysis carried out in Abaqus software in terms of plastic hinge development. A reinforced concrete pile was located at the middle of the soil system carrying both axial and El Centro earthquake record earthquake loading. In each case, the effects of pile length, the fixity of the pile head and the thickness and location of the liquefied soil layer were investigated. The results of this study were purely based on numerical simulation; therefore, to ensure appropriate values, both pile and soil parameters were chosen from previous case histories. The soil response obtained from the soil-pile interaction models was performed through the $p-y$ curves and described. A summary of the work and conclusions of this research are presented in the following.

For cases II and III, the locations of large the bending moment were attained at the interface between the liquefiable and nonliquefiable layers.

It was shown that in case I, the maximum bending moment was likely to occur at the middle of the pile on the depth of the liquefiable soil for both free- and fixed-head piles. For all three cases, it was concluded that pile length and the thickness of the liquefiable layer have little influence on the maximum lateral displacements. It was also shown that the pile length has no effect on the location of the maximum bending moment.

Soil conditions determine the location of plastic hinges, usually at the location of the maximum moment or at the boundaries
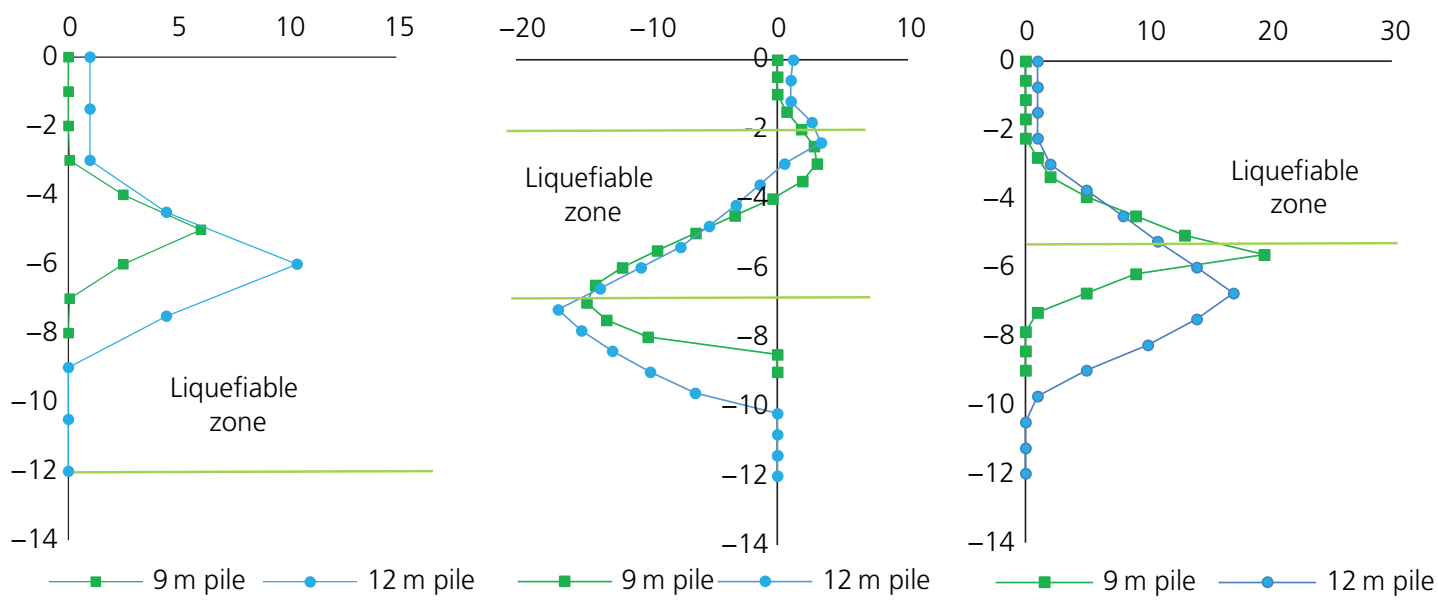

Figure 16. Pile maximum curvature distribution: $\mathrm{m}^{-1}$ 
between the liquefiable and non-liquefiable layers. However, the location of plastic hinges can be affected by a variety of factors, such as material properties, pile length and thickness of the liquefied soil layer. It was also found that the length of plastic hinges $L_{\mathrm{p}}^{*}$ is related to soil conditions and the increase in liquefiable soil depth is due to increase in the maximum moment.

\section{REFERENCES}

Abaqus Inc. (2012) Abaqus User's Manual - Standard Version 6.12. Abaqus Inc, Dassault Systèmes Simulia Corp., Providence, RI, USA.

Abdoun TH and Dobry R (2002) Evaluation of pile foundation response to lateral spreading. Soil Dynamics and Earthquake Engineering 22(9-12): 1051-1058.

AIJ (Architectural Institute of Japan) (2001) Recommendations for Design of Building Foundations. AIJ, Tokyo, Japan.

ATC (Applied Technology Council) (1996) Improved Seismic Design Criteria for California Bridges: Provisional Recommendations. ATC, Redwood City, CA, USA, Report no. ATC-32.

Banerjee S and Shirole O (2014) Numerical analysis of piles under cyclic lateral load. Indian Geotechnical Journal 44(4): 436-448.

Bhattacharya S (2003) Pile Instability during Earthquake Liquefaction. $\mathrm{PhD}$ thesis, University of Cambridge, Cambridge, UK.

Bhattacharya S and Goda K (2013) Probabilistic buckling analysis of axially loaded piles in liquefiable soils. Soil Dynamics and Earthquake Engineering 45: 13-24.

Bhattacharya S and Madabhushi SPG (2008) A critical review of methods for pile design in seismically liquefiable soils. Bulletin of Earthquake Engineering 6: 407-446.

Bhattacharya S, Madabhushi SPG and Bolton MD (2004) An alternative mechanism of pile failure in liquefiable deposits during earthquakes. Géotechnique 54(3): 203-213.

Bhattacharya S, Bolton MD and Madabhushi SPG (2005) A reconsideration of the safety of the piled bridge foundations in liquefiable soils. Soils and Foundations 45(4): 13-25.

Blandon CA (2007) Seismic Analysis and Design of Pile Supported Wharves. $\mathrm{PhD}$ thesis, University of California San Diego, San Diego, CA, USA.

Booth E (1994) Concrete Structures in Earthquake Regions, 1st edn. Longman Scientific, Harlow, UK.

BSI (2004) BS EN 1998-1:2004: Eurocode 8: Design of structures for earthquake resistance. General rules, seismic actions and rules for buildings. BSI, London, UK.

BTL Committee (2000) Study on Liquefaction and Lateral Spreading in the 1995 Hyogoken-Nambu Earthquake. Building Research Institute, Ministry of Construction, Tokyo, Japan, Building Research Report No. 138.

Budek AM, Priestley MJN and Benzoni G (2000) Inelastic seismic response of bridge drilled-shaft RC pile/columns. Journal of Structural Engineering 126(4): 510-517.

Caltrans (California Department of Transportation) (2006) Seismic Design Criteria. Caltrans, Sacramento, CA, USA.

Dash S, Bhattacharya S and Blakeborough A (2010) Bending buckling interaction as a failure mechanism of piles in liquefiable soils. Soil Dynamics and Earthquake Engineering 30: 32-39.

Dash S, Rouholamin M, Lombardi D and Bhattacharya S (2017) A practical method for construction of $p-y$ curves for liquefiable soils. Soil Dynamics and Earthquake Engineering 97: 478-481.

Dobry R, Taboada V and Liu L (1995) Centrifuge modelling of liquefaction effects during earthquakes. In Earthquake Geotechnical Engineering: Proceedings of IS-Tokyo '95, the First International Conference on Earthquake Geotechnical Engineering (Ishihara K (ed.)). Balmeka, Rotterdam, the Netherlands, vol. 3, pp. 1291-1326.

Fan K, Gazetas G, Kaynia K, Kausel E and Ahmad S (1991) Kinematic seismic response of single piles and pile groups. Journal of Geotechnical Engineering 117(12): 1860-1879.
Fardis MN (2009) Seismic Design, Assessment and Retrofitting of Concrete Buildings: Based on EN-Eurocode 8. Springer, Dordrecht, the Netherlands. Fema (Federal Emergency Management Agency) (2000) NEHRP Recommended Provisions and Commentary for Seismic Regulations for New Buildings and Other Structures. Fema, Washington, DC, USA, Fema 369

Finn WDL and Fujita N (2002) Piles in liquefiable soils: seismic analysis and design issues. Soil Dynamics and Earthquake Engineering 22(9-12): 731-742.

Goh S and O'Rourke T (1999) Limit state model for soil-pile interaction during lateral spread. Proceedings of 7th US-Japan Workshop on Earthquake Resistant Design of Lifeline Facilities and Countermeasures against Soil Liquefaction, Seattle, WA, USA, pp. 237-260.

Hamada M (1992) Large ground deformations and their effects on lifelines: 1983 Nihonkai-Chubu earthquake. In Case Studies of Liquefaction and Lifeline Performance during Past Earthquakes: Volume 1 Japanese Case Studies (Hamada M and O'Rourke TD (eds)). National Centre for Earthquake Engineering Research, Buffalo, NY, USA, Technical Report NCEER-92-0001, pp. 4i-4-85.

Helwany S (2007) Applied Soil Mechanics with ABAQUS Applications. Wiley, Toronto, ON, Canada.

Hetényi M (1946) Beams on Elastic Foundation: Theory with Applications in the Fields of Civil and Mechanical Engineering. University of Michigan Press, Ann Arbor, MI, USA.

Ishihara K (1997) Terzaghi oration: geotechnical aspects of the 1995 Kobe earthquake. Proceedings of ICSMFE, Hamburg, Germany, pp. 2047-2073.

JRA (Japanese Road Association) (2002) Specification for Highway Bridges: Part V: Seismic Design. JRA, Tokyo, Japan.

Kramer SL (2014) Performance-based Design Factors for Pile Foundations. Washington State Department of Transportation, Olympia, WA, USA, WSDOT Research Report WA-RD 827.1

Lombardi D and Bhattacharya S (2014) Modal analysis of pile-supported structures during seismic liquefaction. Earthquake Engineering \& Structural Dynamics 43(1): 119-138.

Lombardi D and Bhattacharya S (2016) Evaluation of seismic performance of pile-supported models in liquefiable soils. Engineering \& Structural Dynamics 45: 1019-1038.

Maheshwari BK and Sarkar R (2011) Seismic behaviour of soil-pile-structure interaction in liquefiable soils: a parametric study. International Journal of Geomechanics 11(4): 335-347.

McGann CR, Arduino P and Helnwein PM (2012) Development of Simplified Analysis Procedure for Piles in Laterally Spreading Layered Soils. Pacific Earthquake Engineering Research Center, University of California, Berkeley, CA, USA, Peer Report 2012/05.

Priestley MJN, Seible F and Calvi G (1996) Seismic Design and Retrofit of Bridges. Wiley, New York, NY, USA.

Rahmani A and Pak A (2012) Dynamic behaviour of pile foundations under cyclic loading in liquefiable soils. Computers and Geotechnics 40(2012): 114-126.

RTRI (Railway Technical Research Institute) (1999) Design Standard for Railway Facilities - Seismic Design. RTRI, Tokyo, Japan.

Rollins KM, Gerber TM, Lane JD and Ashford SA (2005) Lateral resistance of a full-scale pile group in liquefied sand. Journal of Geotechnical and Geoenvironmental Engineering 131: 115-125.

Sarkar R and Maheshwari BK (2012) Effects of separation on the behaviour of soil-pile interaction in liquefiable soils. International Journal of Geomechanics 12(1): 1-13.

Sarkar R, Bhattacharya S and Maheshwari BK (2014) Seismic requalification of pile foundations in liquefiable soils. Indian Geotechnical Journal 44(2): 183-195.

Takahashi A, Kuwano Y and Yano A (2002) Lateral resistance of buried cylinder in liquefied sand. Proceedings of the International Conference on Physical Modelling in Geotechnics, ICPMG-02, St John's, NL, Canada. 
Geotechnical Research

Volume 4 Issue GR4
Seismic analysis of pile in liquefiable soil

and plastic hinge

Rostami, Hytiris, Bhattacharya and Giblin
Tokimatsu K and Asaka Y (1998) Effects of liquefaction-induced ground displacements on pile performance in the 1995 Hyogeken-Nambu earthquake. Soils and Foundations 38: 163-177.

Yasuda S, Terauchi T, Morimoto H, Erken A and Yoshida N (1998)

Post liquefaction behaviour of several sand. In Proceedings of the 11th European Conference on Earthquake Engineering (Bisch P, Labbé P and Pecker A (eds)). Balkema, Rotterdam, the Netherlands (CD-ROM).
Yoshida N and Hamada M (1990) Damage to foundation piles and deformation pattern of ground due to liquefaction induced permanent ground deformation. Proceedings of the 3rd Japan-US Workshop on Earthquake Resistant Design of Lifeline Facilities and Countermeasures for Soil Liquefaction San Francisco, NCEER-91-0001, pp. 147-161.

Zhang J and Hutchinson TC (2012) Inelastic pile behaviour with and without liquefaction effects. Soil Dynamics and Earthquake Engineering 128(5): 595-602

\section{How can you contribute?}

To discuss this paper, please submit up to 500 words to the editor at journals@ice.org.uk. Your contribution will be forwarded to the author(s) for a reply and, if considered appropriate by the editorial board, it will be published as a discussion in a future issue of the journal. 